\title{
Using Intragastric Meal Distribution and Antral Contractility for Enhanced Gastric Emptying Analysis
}

\author{
Patrick M. Colletti, FACNM, FSNMMI
}

Keck School of Medicine of USC, Los Angeles, California

See the associated article on page 138.

I this issue of Journal of Nuclear Medicine Technology, Orthey et al. (1) investigate the dynamic relationship of the fundal reservoir and the antral pump in solid-meal gastric physiology in 20 healthy volunteers. Special attention was focused on dynamic antral contraction scintigraphy (DACS). Interestingly, "For the DACS imaging, each subject was allowed to choose whether an upright standing or seated position was most comfortable and then instructed to remain as still as possible in that position for the $20 \mathrm{~min}$ of DACS imaging." No further comment on any potential differences in upright versus supine gastric emptying were presented, despite the obvious gravitational advantage of the upright position for fundal emptying, given that the authors were interested in isolated antral function.

Antral contractions may of course be directly visualized nonquantitatively via fluoroscopy with nonphysiologic barium suspensions or iodinated contrast agents, and elastogastrography may be used for antral frequency analysis (2). Because the normal antrum contracts at about 3 cycles per minute during gastric emptying, antral frequency analysis cannot be determined by routine 1-image-per-minute solid gastricemptying examinations.

On the other hand, for this gastric-emptying study, antral contractions were monitored at the relatively rapid rate of 1 image per $3 \mathrm{~s}(3-5)$, and thus, the acquired data time resolution far exceeded the standard 1-image-per-minute acquisition rate typically used. This rapid, dynamic data collection was then frequency-analyzed using fast Fourier techniques to identify a relatively novel physiologically determined gastric antral region of interest, as compared with the more usually selected arbitrary anatomic mid-stomach fundal-antral border.

The onset and frequency of antral contractions could then be identified and measured, and a normal database created. Authors speculate on the potential clinical benefits of dynamic antral contraction analysis as compared with routine gastricemptying examinations. Perhaps in the future we will collect and manage gastric-emptying data in a manner similar to firstpass radionuclide angiography, with antral ejection fraction and phase analysis and reporting. We should look forward to the results of future clinical trials targeting the application of antral function analysis to outcomes in patients with dyspepsia.

\section{DISCLOSURE}

No potential conflict of interest relevant to this article was reported.

\section{REFERENCES}

1. Orthey P, Dadparvar S, Parkman HP, Maurer AH. Enhanced gastric emptying scintigraphy to assess fundic accommodation using intragastric meal distribution and antral contractility. J Nucl Med Technol. 2019;47:138-143.

2. Parkman HP, Hasler WL, Barnett JL, Eaker EY; American Motility Society Clinical GI Motility Testing Task Force. Electrogastrography: a document prepared by the Gastric Section of the American Motility Society Clinical GI Motility Testing Task Force. Neurogastroenterol Motil. 2003;15:89-102.

3. Urbain JL, Vekemans MC, Bouillon R, et al. Characterization of gastric antral motility disturbances in diabetes using a scintigraphic technique. J Nucl Med. 1993;34:576-581

4. Parkman HP, Miller MA, Trate DM, et al. Effect of gastric acid suppressants on human gastric motility. Gut. 1998;42:243-250.

5. Parkman HP, Trate DM, Knight LC, Brown KL, Maurer AH, Fisher RS. Cholinergic effects on human gastric motility. Gut. 1999;45:346-354

Received Jan. 21, 2019; revision accepted Jan. 30, 2019.

For correspondence or reprints contact: Patrick M. Colletti, Keck School of Medicine of USC, 1200 N. State St., LAC+USC Medical Center GH 3566, Los Angeles, CA 90033.

E-mail: colletti@usc.edu

Published online Apr. 24, 2019.

COPYRIGHT (c) 2019 by the Society of Nuclear Medicine and Molecular Imaging.

DOI: 10.2967/jnmt.118.225029 